\title{
Incidentally discovered intrathoracic extra-adrenal pheochromocytoma during preoperative screening
}

\author{
Merces Assumpcao-Morales, Vinuta Mohan, Tasneem Zahra
}

\begin{abstract}
Introduction: We are reporting a case of an incidental mass later diagnosed as an extradural pheochromocytoma at T2-T4 level during a presurgical work up for a gynecological procedure. Only a few cases of extradural paravertebral tumors are described in literature. Case Report: This is a clinical case of an asymptomatic 26-year-old female with an incidental finding of thoracic mass in chest $X$-ray during preoperative screening for myomectomy. Work up for this mass showed elevated plasma and urinary metanephrine levels which was consistent to pheochromocytoma. Computed tomography, magnetic resonance imaging and metaiodobenzylguanidine scans demonstrate a mass originating from thoracic spine with cord compression, no adrenal mass, multifocal disease or metastasis. Prior to surgery, the patient was treated with phenoxybenzamine and metoprolol to decrease hemodynamic instability during surgical procedure and also embolization to the arteries supplying the mass to decrease intraoperative bleeding. Patient
\end{abstract}

Merces Assumpcao-Morales ${ }^{1}$, Vinuta Mohan², Tasneem Zahra $^{3}$

Affiliations: ${ }^{1} \mathrm{MD}$, Department of Internal Medicine, PGY2, Lincoln Medical and Mental Health Center, Bronx, New York, USA; ${ }^{2} \mathrm{MD}$, FACE, Department of Endocrinology, Lincoln Medical and Mental Health Center, Bronx, New York, USA; ${ }^{3} \mathrm{MD}, \mathrm{FACP}, \mathrm{FACE}$, Chief of the Department of Endocrinology, Lincoln Medical and Mental Health Center, Bronx, New York, USA.

Corresponding Author: Merces Assumpcao-Morales, MD, Department of Internal Medicine, Lincoln Medical and Mental Health Center, 234 East 149 Street, Bronx, New York, 10451; Ph: 516-724-6002; Fax: 718-579-5170; Email: mercesca@hotmail.com

Received: 20 May 2013

Accepted: 20 June 2013

Published: 01 November 2013 remained stable during and after the removal of the mass. Pathology report confirmed presence of a 6-cm extradural pheochromocytoma at the T2-T4 location. Conclusion: A high index of suspicion for pheochromocytoma was crucial for the diagnosis in this patient. It is well known that the induction of anesthesia, use of certain drugs and manipulation of the tumor can lead to increase of catecholamine release with serious hemodynamics abnormalities and increase rate of mortality, complications that can be decreased with proper medical management. We report a very rare location of a pheochromocytoma. A high index of suspicion was crucial for the diagnosis and proper treatment in this asymptomatic patient.

Keywords: Pheochromocytoma, Extra-adrenal, Paravertebral tumor

$$
* * * * * * * * *
$$

Assumpcao-Morales M, Mohan V, Zahra T. Incidentally discovered intrathoracic extra-adrenal pheochromocytoma during preoperative screening. International Journal of Case Reports and Images 2013;4(11):627-630.

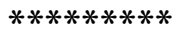

doi:10.5348/ijcri-2013-11-396-CR-10

\section{INTRODUCTION}

Herein, we report a rare case of an incidental mass later diagnosed as an extradural pheochromocytoma at $\mathrm{T} 2-\mathrm{T} 4$ level during a presurgical work up for a gynecological procedure. A high index of suspicion for pheochromocytoma prompted an evaluation to establish the diagnosis in this asymptomatic patient. It is well known that the induction of anesthesia, use of certain drugs and indirect or direct manipulation of the tumor 
can lead to increase of catecholamine release with serious hemodynamics consequences leading to significant complications and increased risk of mortality, all of which can be avoided with appropriate diagnosis and medical management. The supra diaphragmatic location of an extra-adrenal pheochromocytoma is already known to be very rare, and only a few cases of extradural paravertebral tumors are described in literature.

\section{CASE REPORT}

An otherwise healthy 26-year-old female with a past medical history of uterine fibroids and cholelithiasis underwent presurgical clearance for resection of uterine fibroids and was found incidentally to have a $5.8-\mathrm{cm}$ left lung apical mass on chest X-ray. Computed tomography (CT) scan of chest revealed an expanding tumor that originates at T2 level with partial destruction of the left pedicle. The patient was admitted for further work up and resection of the mass when she was noticed to be hypertensive along with intermittent tachycardia. Patient did not have any symptoms such as headache, palpitations, diaphoresis or neurologic abnormalities. Clinical examination was remarkable for a systolic murmur in aortic area, lower left and right sternal border grade $1 / 6$. Laboratory evaluation was significant for elevated urine and plasma metanephrine levels. An magnetic resonance imaging (MRI) scan of the thoracic spine demonstrated T2-T3 dumbbell shaped mass suggesting cord compression with flattening (Figure 1). Images studies failed to demonstrate adrenal tumor or metastasis. Metaiodobenzylguanidine scan was requested and patient discharged with follow-up in endocrinology and neurosurgery clinic. Metaiodobenzylguanidine scan demonstrated intense radiotracer accumulation in left upper chest, with no other activity elsewhere in the body cavity which reassured the diagnosis of isolated extra-adrenal pheochromocytoma. Surgical intervention was indicated. Preceding surgery, she was treated with phenoxybenzamine and metoprolol to decrease hemodynamic instability one would expect intraoperatively. An angiogram with embolization to the arteries supplying this chromaffin tissue to prevent excessive intraoperative bleeding was performed two days prior to surgery. T2-T4 laminectomy and decompression of the tumor was performed with no intraoperative complications. Postoperative course was complicated with pneumonia, which responded well with antibiotics. Pathology report confirmed presence of a 6-cm extradural pheochromocytoma at the T2-T4 location.

\section{DISCUSSION}

Pheochromocytoma is a rare catecholamine-secreting tumor derived from chromaffin cells. They are known to follow the $10 \%$ rule: $10 \%$ bilateral, $10 \%$ malignant,
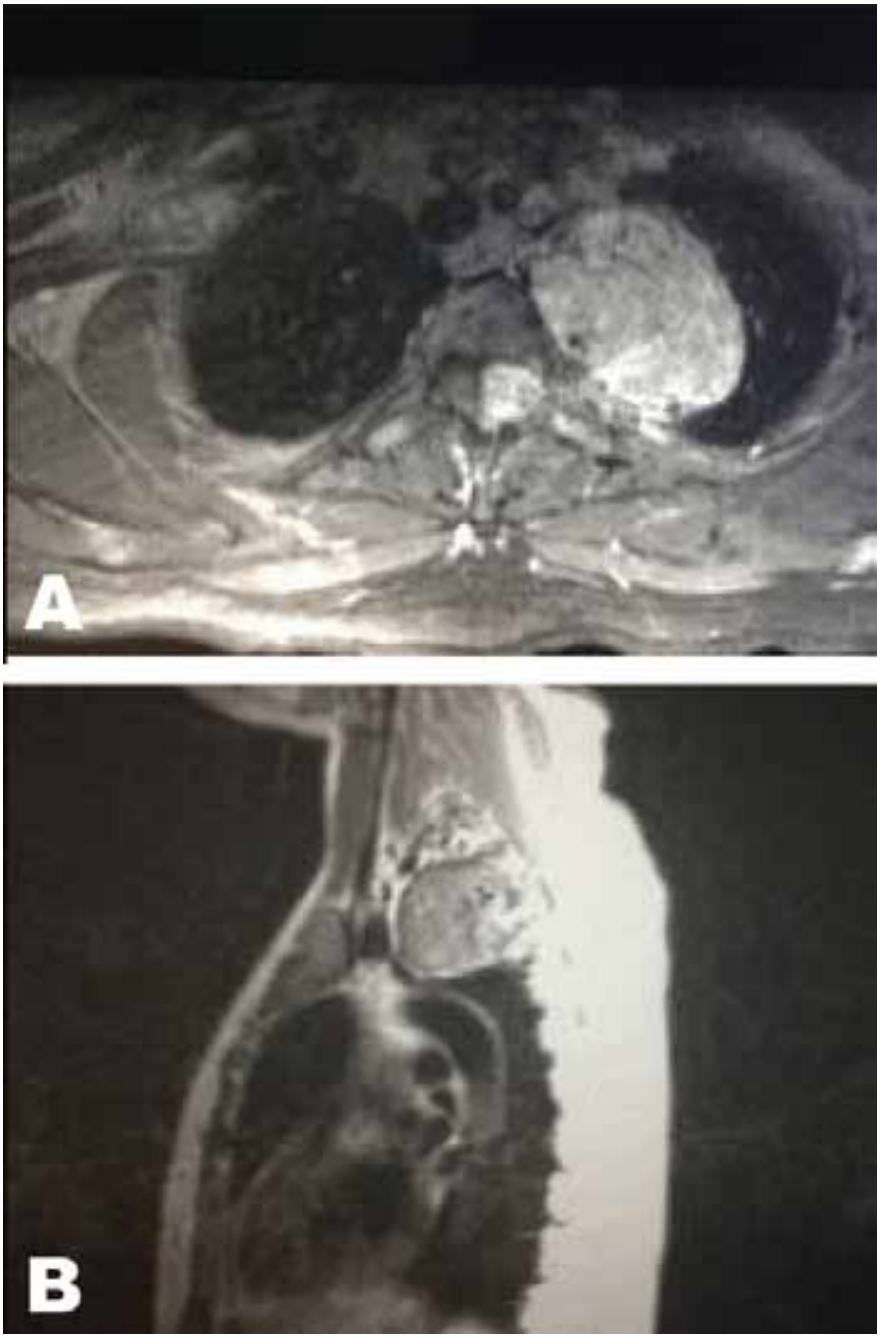

Figure 1: Thoracic spine magnetic resonance imaging scan showing a large dumbbell shaped tumor extending through the left T2-T3 neuroforamina with cord compression (A) Axial view, (B) Sagittal view.

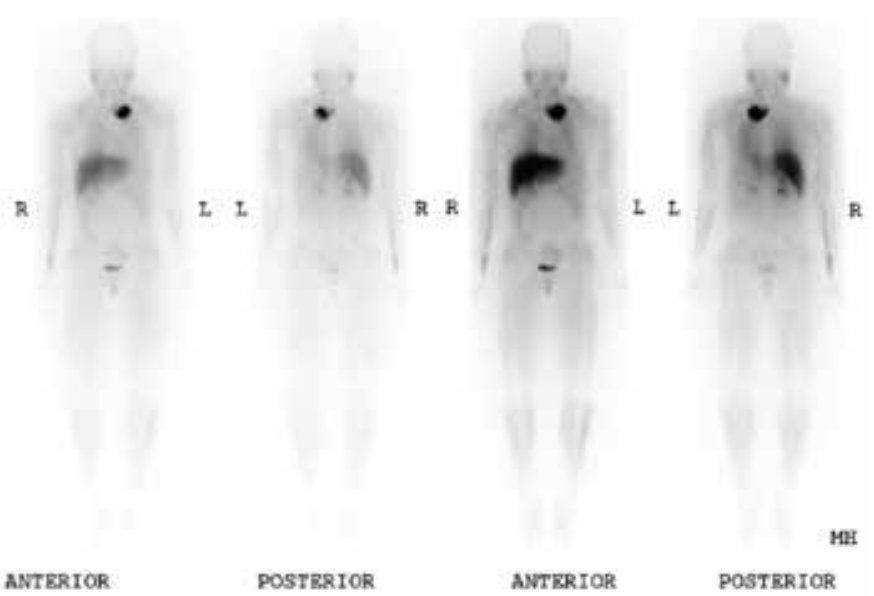

Figure 2: Iodine-123 metaiodobenzylguanidine scan showing large focal region of intense radiotracer accumulation in the left upper chest. 
$10 \%$ in children, as well as an association that has been described with familial syndromes, known as multiple endocrine neoplasia type II. New studies suggest a higher incidence of extra-adrenal location, $15-20 \%$ extraadrenal location in the adults and even $30 \%$ in children $[1,2]$. The diagnosis of adrenal pheochromocytoma are most common in the $4-5^{\text {th }}$ decade of life while extraadrenal sites occur earlier, in the 2nd or 3rd decade [1, 2]. The extra-adrenal locations have been associated with a higher incidence of metastasis and multicentricity. Multicentricity pattern in $15-24 \%$ of extra-adrenal tumors was noted in a study conducted by Whalen et al. [2]. Eighty-five percent of extra-adrenal tumors are located in the retroperitoneum, usually arising from the organ of Zuckerkandl-extra-adrenal sympathetic paraganglionic organ located at the origin of the inferior mesenteric artery. Only $1 \%$ is located above the diaphragm. The spinal canal can be affected throughout its course, although very uncommon, with the intradural lumbosacral region being the most described location. In a review of literature only nine cases of thoracic extradural pheochromocytoma were reported [3]. Patient symptoms include paroxysmal hypertension, orthostatic hypotension, anxiety, tremors, sweating and palpitations due to increase levels of norepinephrine. Other symptoms are related to compression of adjacent structures by the tumor. The measurements of plasma and/or urinary fractioned metanephrines are the recommended first line tests for the diagnosis of pheochromocytoma. Studies have shown that they have a higher diagnostic sensitivity when compared with urinary and plasma catecholamines as well as urinary vanillylmandelic acid [4]. Imaging is necessary in order to define location, as well as to exclude multicentricity and metastasis. In a prospective study that analyzed 104 patients over 48 years with pheochromocytoma, imaging modalities, such as computed tomography and magnetic resonance imaging scans demonstrated specificity above 97\% [5]. Computed tomography scan demonstrated a higher sensitivity, but was not statistically significant. Functional imaging is always required to confirm the diagnosis and rule out metastasis, the most common being scintigraphy with iodine-131 metaiodobenzylguanidine. Positron emission tomography (PET) scan is also is showing promise as a diagnostic modality. Complete surgical resection is the treatment of choice for extra-adrenal as well as adrenal pheochromocytoma. It is important to be aware of risk of hemodynamic instability during surgery that can lead to multiorgan failure as a main complication. Preparation should start two weeks prior to surgery and include use of alpha blockers, such as prazosin or phenoxybenzamine in order to provide full alpha adrenergic blockage and restoration of blood volume [6, 7]. Later consideration in starting beta blockers is also recommended in order to avoid arrhythmia. Following surgery, lifelong followup will be required aimed at detecting recurrence of the tumor or metastasis since it can happen anytime after surgery.

\section{CONCLUSION}

A high index of suspicion for pheochromocytoma was crucial for the diagnosis in this asymptomatic patient. Since direct or indirect manipulation of the tumor can lead to hemodynamic instability and increase in mortality patients should receive proper medical treatment prior to surgery in order to avoid and reduce those complications. This patient was proper diagnosed and treated prior to surgery remaining stable during per and postoperative course.

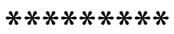

\section{Author Contributions}

Merces Assumpcao-Morales - Acquisition of data, Analysis and interpretation of data, Drafting the article, Critical revision of the article, Final approval of the version to be published

Vinuta Mohan - Analysis and interpretation of data, Critical revision of the article, Final approval of the version to be published

Tasneem Zahra - Analysis and interpretation of data, Critical revision of the article, Final approval of the version to be published

\section{Guarantor}

The corresponding author is the guarantor of submission.

\section{Conflict of Interest}

Authors declare no conflict of interest.

\section{Copyright}

(C) Merces Assumpcao-Morales et al. 2013; This article is distributed under the terms of Creative Commons attribution 3.0 License which permits unrestricted use, distribution and reproduction in any means provided the original authors and original publisher are properly credited. (Please see www.ijcasereportsandimages.com/ copyright-policy.php for more information.)

\section{REFERENCES}

1. Disick GI, Palese MA. Extra-adrenal pheochromocytoma: Diagnosis and management. Curr Urol Rep 2007 Jan;8(1):83-8.

2. Whalen RK, Althausen AF, Daniels GH. Extra-adrenal pheochromocytoma. J Urol 1992 Jan;147(1):1-10.

3. Conti P, Mouchaty H, Spacca B, Buccoliero AM, Conti R. Thoracic extra adrenal paragangliomas: A case report and review of the literature. Spinal Cord 2006 Feb;44(2):120-5.

4. Pacak K, Eisenhofer G, Ahlman H, et al. Pheochromocytoma: Recommendations for clinical practice from the First International Symposium. October 2005. Nature clinical practice endocrinology \& metabolism 2007 Feb;3(2):92-102. 
5. Goldstein RE, O’Neill JA Jr, Holcomb GW 3rd, et al. Clinical experience over 48 years with pheochromocytoma. Ann Surg 1999 Jun;229(6):75564.

6. Baraka A. Undiagnosed pheochromocytoma complicated with perioperative hemodynamic crisis and multiiorgan failure. Pheochromocytoma - A new view of the old problem. Jose Fernando Martin 2011.

7. Wen J, Li HZ, Ji ZG, Mao QZ, Shi BB, Yan WG. A decade of clinical experience with extra adrenal paragangliomas of retroperitoneum: Report of 67 cases and literature review. Urol Ann 2010 Jan;2(1):12-6.
Access full text article on other devices

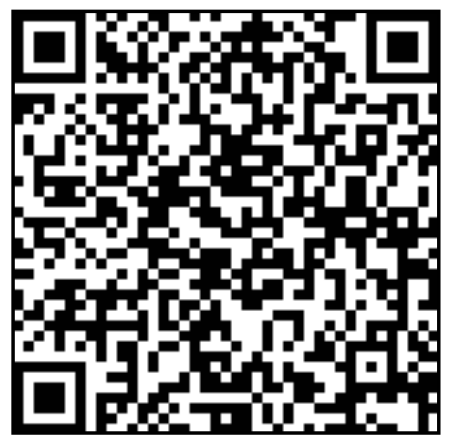

Access PDF of article on other devices

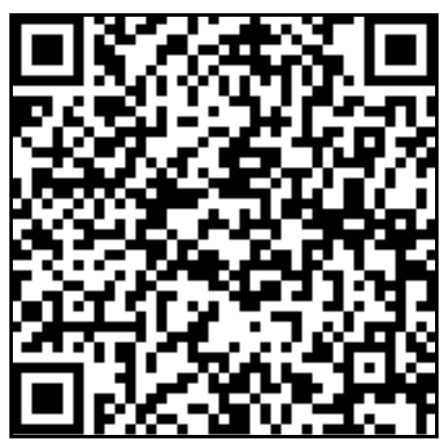

